\title{
On Several Reflection Factors during the Interior Design of Green Residence
}

\author{
Gao Shanshan \\ Jiangyin Polytechnic College \\ Xicheng Road \#168, Jiangyin City, Jiangsu Province ,214405,China
}

\begin{abstract}
Nowadays, with the rapid development of the society and economy, the living standards of people increase rapidly. People are gradually pursuing green and environmental living concepts rather than the extensive type living modes. Due to the increase of people's cognition of scientific development concept as well as the gradually increasing demands on residential interior design, the concept of green residence comes into people's mind. As the development tendency of future interior design, green residence can be environmental-friendly and increase the greenery and comfort to the house, thus being more and more welcomed in the home market. This paper analyzes and explores some questions concerned during the green residential interior design by starting from the concept of green residential interior design.
\end{abstract}

Key word: green residence; interior design; factors; reflections

\section{I.INTRODUCTION}

The scientific concept of green residential interior design is more and more welcomed by the people since the green residential interior design that conforms to the nature and ecology is the essential demands of civilizational development of human society. It reduces the pollutions to natural environment; meanwhile it increases the internal physical environmental quality of green residence, strengthen the fresh quality of internal house and lengthen the average life span of people. Therefore, the scientific green residential interior design is widely-welcomed by people, which will become popular in the sustainable development of natural ecology. This paper summarizes the concept and features of green residences, the design principles of green residences as well as the future development tendencies of green residential interior design.

\section{Summarizing the features of green residence}

Up to now, there is no clear definition and classification on green residence in China. However, the concept of green residence has been widely-accepted and applied in home decoration industry with the increase of environmental-protection consciousness. Generally speaking, green residence refers to the healthy residence that ensures the physical health and natural comfort of residents without harming or destroying the surrounding environment. Undoubtedly, green residence is different from the traditional residence, which mainly lies in its environmental-friendly and energy-saving. To be specific, it has the following distinctive features:

1. Healthy and safe interior environment

The interior environment of green residence can bring safe and health living enjoyment to residents, which can be achieved by environmental-friendly construction materials, green plants and existing natural environment. For example, by constructing interior garden, pool or succulent plants, it can purify the interior air and properly increase greenery.

2. Harmony coexistence with exterior natural environment

The so-called green residence is to provide certain green guarantee to the physical health of residents. During construction, it must apply the green material benefit to the physical health of residents so as to 
ensure the interior air quality and physical health of residence. Green residence will not damage the surrounding natural environment, instead it will maintain the surrounding natural plant and natural scenery as much as possible during the design, such as trees, rivers, streams, flowers and so on, thus being one part of the residence. If without coexistence, it should build houses elsewhere. Green residence can be coexistent with the exterior natural environment with affecting the live and multiply of surrounding plants and animals by the living of human beings.

\section{Complete green and energy-saving system}

Green residence must be environmental-friendly and energy-saving. To realize these functions, the designers should involve relevant concepts and technologies during the design so as to fully apply new technology, craft and realize the unification of water-saving, energy-saving and environmental-friendly. Green residence can reduce the pollution to surrounding environment. By constructing a complete system, it can increase the comfort of the house and satisfy the demands of the residents' high quality demands. Therefore, the selection site and construction of green house should have the features of energy-saving, water-saving, material-saving and equipment-saving.

\section{Longer life span than ordinary residence}

The higher quality of green residence makes it have longer life span than ordinary house for it is hardly damaged by natural disaster and has better water-proof effects and resistance. The effective application of resources and repeated application is another feature of green residence and makes it have longer life span than ordinary house so as to avoid the pollutions to environment and negative influences and pollution. It needs no higher maintenance costs and easier maintenance.

\section{Principles of green residence}

Due to the excellent functions and practicability, green residence is widely-welcomed by people. Designers should obey the following principles during design so as to attach it with greater glamour.

\section{Concept of respect for nature and people-oriented}

During the design of green residence, it should obey the concept of people-oriented for people are the residents and it should involve various factors such as green, environmental-friendly and energy-saving so as to fully implement the concept of health and green resident. To realize this aspect, people should fully respect the nature by taking reference of natural elements, environmental-friendly material, green plants, energy-saving technology, green technology etc so as to optimize the structure and increase the utility rate of space, increase functionality and practicality of the residences and increase its ventilation effect so that it can satisfy people's living requirement or even the effect of warm in winter and cold in summer.

Besides, it should be people-oriented. Under the premise of fully considering the living demands of the elders and children as well as their physical health, it should apply the interior structure, design style, construction material and color collocation that is benefit to the body so as to make their life comfort, enjoyable, relax and nature. The concrete demand of residents is the design aim of designers. Designers should combine the careers, characteristics and physical conditions of the resident so as to comprehensively consider the design plan and build am appropriate green residence that is most suitable for the users.

2. As more green environmental-friendly materials as possible

The interior environment of green residence must be good, which means the designers should use more 
green environmental-friendly materials as possible during the home decoration. At present, there are many decorational materials that are excess the pollution indicators from a tile to wood board and curtain wall. If these materials cannot satisfy the the environmental demand, it would definitely increase pollution index, which will harm the body of resident. Therefore, designers should select the basic materials conforming to the environmental index and beautify the house with renewable material. For some users who like natural design, it can increase structures of $\log$ and natural bricks or stones so as to reduce the usage of modern home decoration materials and increase environmental-friendly effect, which can greatly reduce the harm to human body.

3. As more green environmental-friendly technologies as possible

In the green residence, it can use various green technologies to realize beautiful and practical residential function.

(1) By apply energy-saving and water-saving technology, it can greatly reduce energy waste.

During the design of green residence, it can apply advanced energy-saving and water-saving technology so as to build up a whole energy-saving system for the house. It can reduce the waste on energy by paving water-saving system and underearth heating. The existing mature relevant technologies have energy-saving circulation system, which can fully apply solar energy, wind energy and electricity energy and reasonable integrated application of natural resources, such as the solar heater, solar lightening system, heat-absorbing system, wind lightening, circulating water-heating equipment and so on so as to realize energy-saving and water-saving. This new technology cannot reduce the waste on common energy; it can also protect environment and save living costs as well.
(2) It can improve the interior air quality and reduce the multiply of harmful bacteria by applying green technology. Some green plants can be planted indoors due to its function of bacteria-killing, insects-protecting and purifying harmful gases so as to ensure the healthy interior environment and absorb fresh air and get away from air-conditioner disease and computer disease.

\section{Applying more green environmental-friendly tools}

The interior environmental pollution because of the furniture is also common in China. In order to put an end to the interior environment pollution, apart from the selection of environmental-friendly material for decoration, it should select some green environmental-friendly furniture so as to reduce the pollution of some harmful gases. During the selection of furniture, cane furniture or non-harmful furniture should be chosen. There should be some knowledge for the materials of furniture. Do not fully rely on import furniture but rather some qualified furniture with inspection certificates and without sharp smell.

\section{Future development tendency of green residential interior design}

Green residence is the basic requirements for the residence in the future which is also the essential tendencies for the development of residence. "Residence should be environmental-friendly and environmental-friendly should be green". The basic national policy of green residence should be a comprehensive covering project on all facets. The interior design should be perfected with the development of new technology, new concept and the advance of social scientific technology.

1. Application of hi-tech and environmental-friendly construction materials

Countries all over the world are studying the new environmental-friendly construction materials and they 
all have the following feature, recyclable, low-consumption and low-cost. Take a new environmental-friendly brick as an example, its source material is the waste ash of the electricity plant and it can turn to better construction brick than ordinary brick by applying new technology, which is not only water-proofing, better thermal insulation and noisy insulation effect as well as better pressure resistance. Another construction brick made by sawdust is half lighter than common brick; it has twice more intensity, noisy-insulation and warming effect of common brick.

2. Water-saving system involving function of sewage water handling.

During the interior design of green residence, the water-supply system can be optimized in the future. By setting the sewage-handling system, it can turn the sewage into recycled water which can be used for wash vegetables, clothes, flowers, cars etc. In this way, water for family use can be effectively recycled to some extent, which can not only save family cost but also save large amount of water resources for the country.

3. Widely and scientifically application of optical energy

The usage of solar energy has long been studied; however, the self-supply of optical energy in modern construction is rare. In German, there is an office building that can realize the sufficient supply of energy by solar energy. The building adopts the apparent heat insulation glass that can transmit most sunlight without making people warm or cold but also maintain the humidity. When it hots in summer, people can roll the curtain to reflect sunlight to make it less hot and decrease the interior temperature.

\section{V . CONCLUSIONS}

Conclusion: green residential interior design has good blueprint in the future for it cannot only effectively increase people's living standard but also saves energy for the country and increase environment protection rate and reduce environment damage. With the development of hi-tech in China, more and more green environmental-friendly materials and technologies will be applied in green residential interior design. Designers should fully grasp the green concept and dare to innovate by new technology and methods to promote the healthy development of green design. It is believed that China will realize great green building coverage in the near future so that people can realize the healthy and happy dream in the concrete practice of green residential interior design.

\section{Acknowledgement}

Fund Type: Explorations on the courses and teaching contents system of interior design and industrial standards connections in teaching project of 2013 Jiangsu higher educational reform research (Project No.:2013JSJG342)

\section{References:}

[1].Cui Chengcheng. On Several Reflection Factors during the Interior Design of Green Residence [J] . Science \& Technology Information,2014,15:70

[2]Xu Hao. Several reflections on the relevant interior design of green residence $[\mathrm{J}]$. Modern Decoration (theory),2012,11:130.

[3] Gu Huailiang, Zhu Miao, Wang Jingming \& Qian Jiangtao. Green residence and residential ecology [A]. Theory and Practice of Construction Project (second volvume)[C].2005.

[4]Zhang Chunhua \& Houxue. Exploration on relevant questions of green residential interior design[J].Modern Decoration (theory),2014,10:43.

[5] Huang Zhibing, Zhu Xiaozhong \& Li Zuyong. Expansion and aim design on the connotations of Green Management [J]. Soft Science, 2004（05） 